\title{
Past climate comes into focus but warm forecast stays put
}

\section{Quirin Schiermeier, Munich}

Fluctuations in global temperature during the past millennium may have been larger and more frequent than previously thought, says a fresh analysis of the climate record.

The analysis is likely to reignite a longstanding controversy over the cause and extent of natural climate variability, scientists say, although the unprecedented nature of global warming since the mid1980s remains unquestioned. The study was conducted by Anders Moberg of Stockholm University, Sweden, and his team (see page 613, and News and Views on page 587 ).

According to an earlier study, which produced the widely cited 'hockey stick' graph (see below), average Northern Hemisphere temperatures during the past millennium were relatively stable until the late nineteenth century, when they began to increase sharply ${ }^{1}$. In 2001, this assessment was used to underpin the most recent report of the Intergovernmental Panel on Climate Change (IPCC) - the scientific branch of the United Nations Framework Convention on Climate Change.

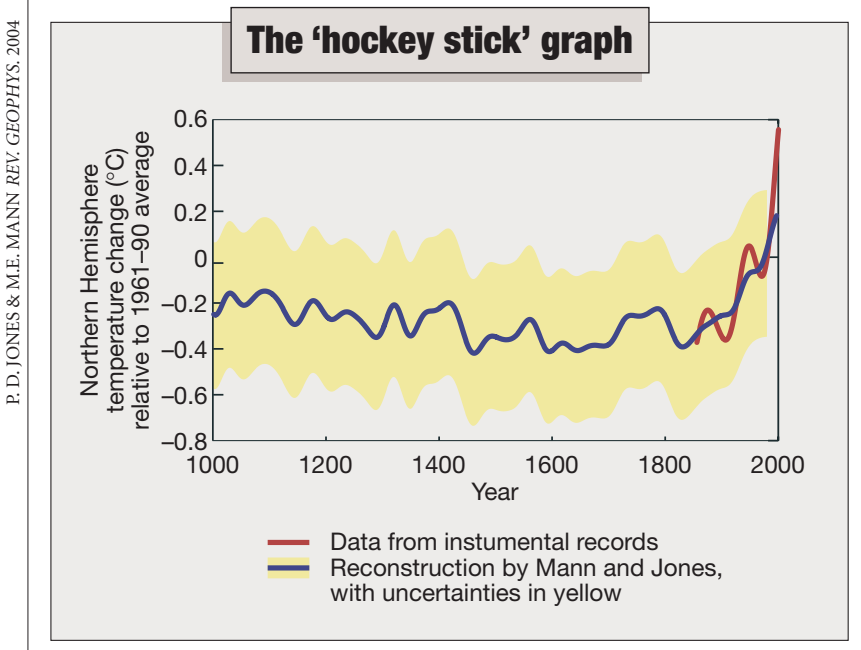

But the Moberg study, which is published just as the Kyoto Protocol comes into effect (see 'Kyoto decks itself for celebration'), suggests that notable climate changes have occurred throughout the recent past. If such natural fluctuations continue in the future, they may "amplify or attenuate anthropogenic climate change significantly", the authors conclude.

Moberg's group used a combination of different 'proxies' to reconstruct decadal and centennial temperature changes. Proxies are climate indicators such as tree rings, pollens and boreholes, and the researchers used each one at the timescale that it records most accurately: tree rings are used for reflecting annual variations, for example, and sediments for longer-term changes. The researchers then used 'wavelet analysis' to combine the timescales in the optimum manner.

"At timescales longer than 80 years, temperature variability seems to have been considerably larger than previously thought," says Moberg.

Previously, different scientists had arrived at different curves for temperature variability over past centuries, depending on the data or models they used $^{2}$. The possibility that they generally underestimated natural climate fluctuations has been one of the main arguments that sceptics use to reject the notion that human activity is responsible for current warming.

This argument has hardly any support in the climate community, however. Many researchers do agree that historic climate

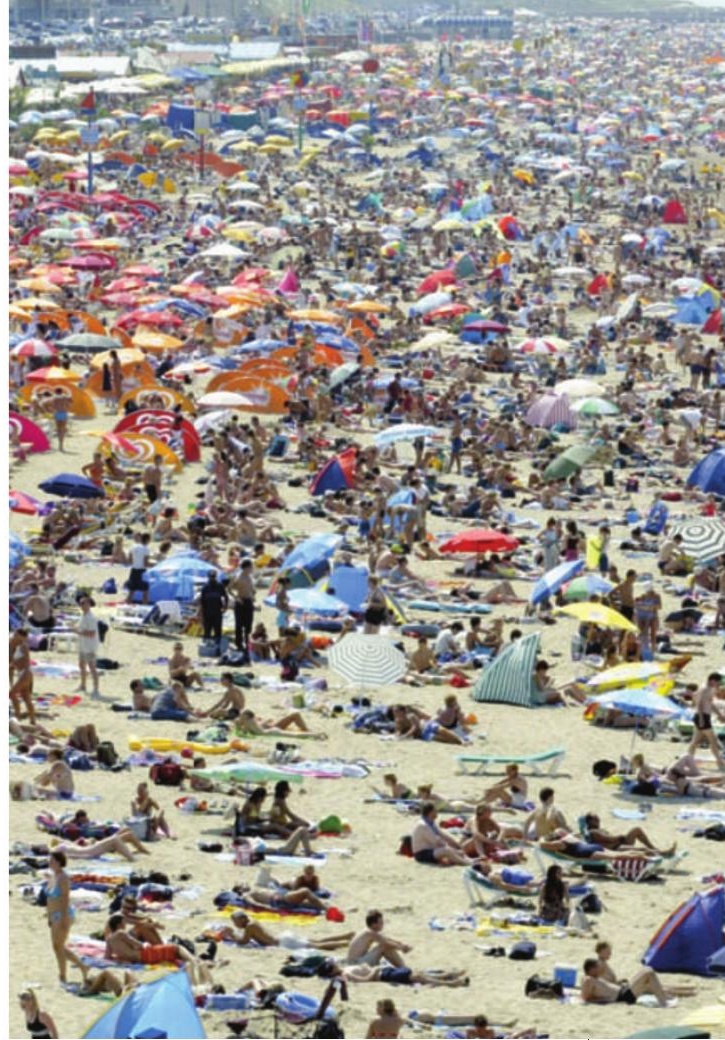

changes may have been underestimated. But the exceptionally strong warming trend since the mid-1980s cannot be explained by natural variability alone, they maintain. "Moberg's reconstruction will help to put the record straight in one of the most contested issues in palaeoclimatology," says Hans von Storch, a climate modeller at the GKSS research centre in Geesthacht, Germany. "But it does not weaken in any way the hypothesis that recent observed warming is a result mainly of human activity."

\section{Moving on}

"We need to understand the past, but some people become fixated," says Phil Jones, a climate researcher at the University of East Anglia in Norwich, UK. "For projecting the rate of climate change in the twenty-first century, it is somewhat irrelevant what happened in medieval times. What really matters is what happened in the twentieth century - and we can expect from that a much warmer climate."

In its 2001 report, the IPCC concluded that "the increase in temperature in the twen-

\section{Kyoto decks itself for celebration as protocol comes into force}

A colourful, international celebration in Kyoto on 16 February will mark the formal entry into force of the climate treaty that bears the city's name.

The Kyoto Protocol, negotiated in 1997, is already beset by scepticism over whether the signatory nations can meet the targets it sets for emissions of carbon dioxide and other greenhouse gases by 2012. And the agreement's effectiveness has been challenged by the refusal of the United States, by far the world's largest emitter of greenhouse gases, to participate.

But backers of the protocol hope that formal implementation will spur efforts to reduce emissions. "We see 16 February as the start of a new era in international efforts to reduce climate change," says Joke Waller-Hunter, executive secretary for the United Nations Framework Convention on Climate Change, the 1992 treaty that the protocol supplements.

The ceremony will open with musical events and a talk detailing efforts taken to curb emissions. There will also be keynote speeches from Waller-Hunter and Wangari Maathai, Kenya's deputy environment minister and winner of last year's Nobel Peace Prize, as well as a live message of support from Japan's prime minister, Junichiro Koizumi.

"The night will give high-level reconfirmations of member countries' commitments," says Takashi Ohmura, an official at Japan's environment ministry. "The protocol will pick up momentum."

It will need to. The latest data on greenhousegas emissions from the industrialized countries that have ratified the agreement suggest that many are falling short of their targets. In Japan, for example, two panels at the Ministry of Economy, Trade and Industry have found that 11 out of 30 industries surveyed, including steel, 


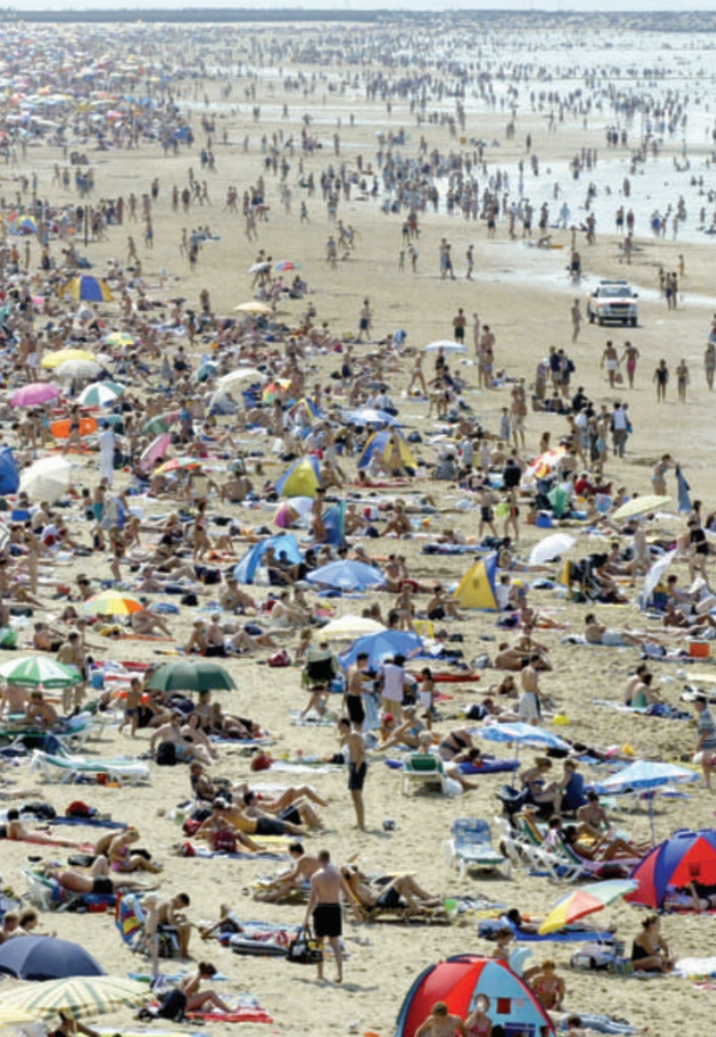

Future summers are set to mirror 2003, when even the Netherlands enjoyed unusual heat.

tieth century is likely to have been the largest in any century during the past 1,000 years."

Moberg's reconstruction is consistent with this assessment. But, says van Storch, the hockey-stick curve, prominently featured in the IPCC's summary for policymakers, has become such a powerful icon that any correction of it will affect the credibility of the IPCC's work. It could give climate sceptics a boost, despite the fact that human-driven global warming is not in doubt (see 'UK climate meeting deems risks 'serious"). The IPCC is likely to raise the issue in May in Beijing at a closed meeting of its working group on the physical basis of climate change.

The hockey-stick reconstruction was derived in 1998 by Michael Mann, a climate researcher now at the University of Virginia in Charlottesville. A small group of critics, including Stephen McIntyre, a Torontobased mineral-exploitation consultant, has since attempted to prove that the graph is

power and electronics, would have difficulty meeting the protocol's targets.

Eileen Claussen, president of the Pew Center on Global Climate Change in Arlington, Virginia, says that the jury is still out on the success of the agreement. The parties to the treaty "have negotiated extremely difficult targets", she says, adding that the protocol's implementation could call attention to this, and motivate stronger actions to reduce emissions.

Attention is now turning to what will happen after the target deadline in 2012 - but there is little sign of a rapprochement between those based on insufficient data and on flawed statistics ${ }^{3}$. Although McIntyre's work is controversial, a recent reanalysis by von Storch partly supports his view ${ }^{2}$. And, in hindsight, many climate researchers believe that it was premature of the IPCC to give the visually suggestive curve so much prominence.

"Mann is a pioneer, whose 1998 study was then the best reconstruction that had ever been done," says Stefan Rahmstorf, a climate researcher at the Potsdam Institute of Climate Impact Research in Germany. But, he adds, the controversy it generates is now out of proportion to its scientific significance.

Rahmstorf adds that even if the hockeystick curve were to be completely wrong and even if all model simulations of the past millennium were fundamentally wrong it would hardly touch ideas about the cause of observed climate change in the twentieth century. Proxy-based reconstruction of past temperatures are important for validating the models that researchers use to predict the future climate. But, he says, "the cause of any particular climate change must be investigated separately. It would be naive to conclude that the observed twentiethcentury warming must have a natural cause just because previous warming events have had one."

Meanwhile, Mann concedes that it is plausible that past temperature variations may have been larger than thought although he insists that Moberg's reconstruction is not free of methodological and statistical problems. He says the issue deserves further investigation and must not be overshadowed by political issues.

"The contrarians would have us believe that the entire argument of anthropogenic climate change rests on our hockey-stick construction," he says. "But in fact some of the most compelling evidence has absolutely nothing to do with it, and has been around much longer than our curve."
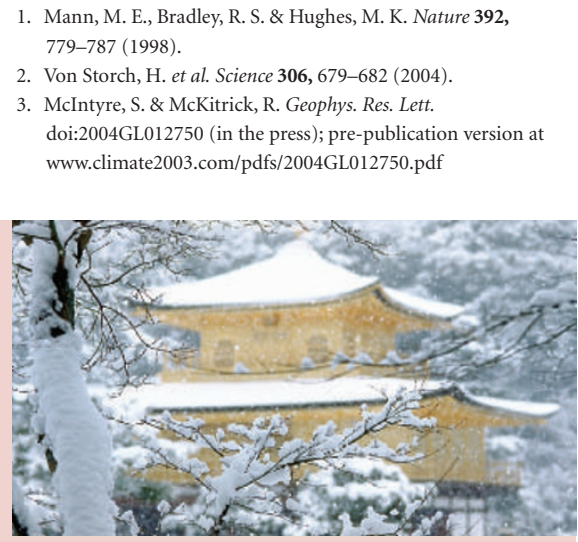

nations that have ratified the agreement and those that have not. Ominously, the United States was not invited to send diplomatic representation to next week's celebrations. "I don't think they would have gone anyway," says Claussen.

David Cyranoski, Tokyo

\section{UK climate meeting deems risks 'serious'}

The risks attached to climate change are "more serious" than was supposed just four years ago, a meeting of top-level climate researchers has told the British government. The scientists add that "major investment is needed now" to mitigate the threat.

The meeting, held at the new headquarters of the UK Met Office in Exeter over

1-3 February, delivered a comprehensive summary of current understanding about global warming to its sponsor, the Department for Environment, Food and Rural Affairs.

Tony Blair, the British prime minister, is expected to use the advice to promote global action on climate change. He will take advantage of Britain's presidency of the European Union, which will begin later this year, and its hosting of July's meeting in Scotland of the G8, the group of eight leading industrialized nations.

But at the Exeter meeting, 200 climate specialists from some 30 countries found scant agreement regarding one government request: a tighter definition of what level of greenhouse gases in the atmosphere would constitute 'dangerous' human interference. Under the 1992 United Nations Framework Convention on Climate Change, the signatory nations - including the United States agreed to act to prevent such a danger, but no one has defined what the word means in the context of the treaty.

Speakers at the meeting opined that levels of 'danger' were too variable between different regions for agreement. "There cannot be a definition of danger acceptable to everyone involved," said Richard Tol, an economist from the University of Hamburg in Germany.

Governments, meanwhile, are unable to agree on an acceptable increase in global temperatures, much less an acceptable concentration of greenhouse gases. In several documents, the council of the European Union has said that a rise of $2^{\circ} \mathrm{C}$ above pre-industrial levels should not be exceeded, although this point of view has not been widely accepted elsewhere.

At Exeter, Malte Meinshausen, a climatepolicy expert from the Swiss Federal Institute of Technology in Zurich, said that models suggest it is "likely" that global temperatures will not rise by more than $2{ }^{\circ} \mathrm{C}$ if the level of greenhouse gases stabilizes at less than the equivalent of 400 parts per million of carbon dioxide - just 20 parts per million above today's value.

The conference also identified research areas that deserve immediate attention, highlighting possible melting of the ice caps on Antarctica and Greenland, and the impact of carbon dioxide on ocean acidification.

Nicola Jones, Exeter 